\title{
Dipyridamole with Low-Dose Aspirin Augments the Infarct Size-Limiting Effects of Simvastatin
}

\author{
Yumei Ye • Bo Long • Jinqiao Qian • \\ Jose R. Perez-Polo • Yochai Birnbaum
}

Published online: 13 January 2011

(C) The Author(s) 2010. This article is published with open access at Springerlink.com

\begin{abstract}
Purpose Statins protect against ischemia-reperfusion injury and limit myocardial infarct size (IS). This effect is dependent on increased generation of adenosine by ecto-5' nucleotidase and downstream activation of cyclooxygenase-2 (COX2). Dipyridamole (DIP) augments the IS-limiting effects of statins by blocking the cellular reuptake of adenosine; whereas aspirin (ASA) attenuates the effect by inhibiting COX2. We studied the effect of acute administration of DIP, ASA and their combination on the IS-limiting effect of simvastatin (SIM).

Methods Rats received oral SIM $(10 \mathrm{mg} / \mathrm{kg} / \mathrm{d})$ or vehicle for 3 days. Rats underwent $30 \mathrm{~min}$ of coronary artery occlusion and $4 \mathrm{~h}$ reperfusion. After $5 \mathrm{~min}$ of ischemia rats received i.v. DIP ( $5 \mathrm{mg} / \mathrm{kg})$, ASA ( $20 \mathrm{mg} / \mathrm{kg}$ or $2 \mathrm{mg} / \mathrm{kg}$ ) or
\end{abstract}

The study was supported by a grant from Boehringer Ingelheim GmbH, Germany.

Y. Ye · B. Long · J. Qian · J. R. Perez-Polo · Y. Birnbaum

Department of Biochemistry and Molecular Biology,

The University of Texas Medical Branch,

Galveston, TX, USA

J. Qian

Department of Anesthesiology, the First Affiliated Hospital of Kunming Medical University,

Yunnan, China

Y. Birnbaum ( $\square)$

Department of Medicine, Section of Cardiology,

Baylor College of Medicine,

1709 Dryden Road, Suite 9.32, BCM620,

Houston, TX 77030, USA

e-mail: ybirnbau@bcm.edu

Y. Birnbaum

Texas Heart Institute, St. Luke's Episcopal Hospital,

Houston, TX, USA
$\mathrm{DIP}+\mathrm{ASA}(2 \mathrm{mg} / \mathrm{kg})$ or vehicle alone. Ischemia area at risk (AR) was assessed by blue dye and IS by TTC. Myocardial samples were analyzed for the activation of Akt, ERK 1/2, endothelial nitric oxide synthase (eNOS), and cyclic-AMPresponse-element-binding-protein (CREB).

Results SIM limited IS. High- or low-dose ASA alone had no effect on IS. DIP alone or with low-dose ASA significantly reduced IS. Low-dose ASA did not attenuate the SIM effect, whereas high-dose ASA completely blocked the effect. The combination of DIP+low-dose ASA+SIM resulted in the smallest IS. Both SIM and DIP+low-dose ASA augmented Akt phosphorylation and their effect was additive. Both SIM and DIP+low-dose ASA augmented eNOS, ERK 1/2 and CREB phosphorylation. Conclusions During acute myocardial ischemia, DIP alone or with low-dose ASA limits IS and does not attenuate the IS-limiting effect of SIM as high-dose ASA.

Key words Reperfusion injury - Statins · Adenosine . Dipyridamole $\cdot$ Aspirin

\section{Introduction}

Dipyridamole (DIP) increases interstitial adenosine concentrations by blocking the cellular reuptake of adenosine [1, 2]. When administered intravenously at high doses (ie, $0.56 \mathrm{mg} / \mathrm{kg}$ over $4 \mathrm{~min}$ ), DIP may exacerbate myocardial ischemia by diverting blood flow from diseased vessels with fixed narrowings to healthier branches undergoing vasodilatation [3]. However, when administered orally at low doses (ie, 300-400 mg/d), DIP has significant antiplatelet effects and causes minimal hemodynamic changes. In the clinical setting, DIP has been used to prevent cardiovascular and cerebrovascular events [2]. 
Recently, the Prevention Regimen for Effectively Avoiding Second Strokes (PRoFESS) study compared the effects of low-dose aspirin (ASA), combined with extended-release DIP (25 mg and $200 \mathrm{mg}$, respectively; twice daily), with the effects of clopidogrel $(75 \mathrm{mg} / \mathrm{d})$ on the secondary prevention of stroke [4]. In both treatment groups, the rates of recurrent stroke and of the combined endpoint-stroke, myocardial infarction (MI), and vascular death-were similar [4]. However, in patients with acute MI, the role of DIP (alone or in combination with low-dose ASA) is less clear.

When given to patients with stable angina or acute coronary syndromes, intracoronary DIP before percutaneous transluminal coronary angioplasty was reported to reduce the risk of abrupt vessel closure [5, 6]. Furthermore, intracoronary DIP reduced the incidence of adverse cardiovascular events in the first $48 \mathrm{~h}$ after balloon angioplasty of small coronary arteries [7]. Yoshida and colleagues [8] also reported that intracoronary DIP administered for acute anterior wall MI before primary percutaneous coronary intervention prevented reperfusion arrhythmia. However, in a study by Thompson and colleagues [9], 202 patients with ST-segment elevation myocardial infarction (STEMI) who were randomly assigned to receive either a continuous intravenous heparin infusion or oral DIP (100 mg, 3 times a day) and ASA $(300 \mathrm{mg} / \mathrm{d}) 24 \mathrm{~h}$ after thrombolytic therapy had similar outcomes. Seven to 10 days after treatment, no differences were observed in clinical events or the rates of patency of the infarct-related artery [9].

The American College of Cardiology (ACC)/American Heart Association (AHA) guidelines for the management of patients with STEMI do not recommend the use of DIP as an antiplatelet agent. According to these guidelines, the combination of low-dose ASA and extended-release DIP is reserved for STEMI patients who have ischemic stroke but do not undergo percutaneous coronary intervention and do not have a cardiac source of embolism or a surgically important carotid stenosis [10-12]. The possibility that DIP could cause coronary steal and augment ischemia in the setting of acute MI may be the reason for these guidelines.

Numerous studies have shown that the hydroxymethyl glutaryl coenzyme A reductase inhibitors (statins) reduce myocardial infarct size [13-18]. The use of statins for patients at high risk for cardiovascular events and for those presenting with acute myocardial infarction is recommended by the guidelines. Previously, we showed that when given orally, DIP augmented the effects of atorvastatin by further reducing the myocardial infarct size (IS) in rats [13]. Statins activate ecto-5'-nucleotidase, which generates adenosine [14]. Inhibition of adenosine receptors not only abrogates the IS-limiting effect of statins [13, 14], but prevents statins from inducing the phosphorylation of the prosurvival mediators ERK 1/2, Akt, and endothelial nitric oxide synthase (eNOS) [15]. The protective, IS-limiting effects of statins are also dependent on the activation of cyclooxygenase-2 (COX2) [16, 17], which can be attenuated by ASA, a nonspecific cyclooxygenase inhibitor, in a dosedependent manner [18].

In our study, we investigated the effects of high- or lowdose ASA and DIP on infarct size, when given alone or in combination with simvastatin (SIM), a hydroxymethyl glutaryl coenzyme A reductase inhibitor (statin), during myocardial ischemia in rats.

\section{Materials and methods}

Animal care

Experiments were performed in male Sprague-Dawley rats. All animals received humane care in compliance with the Guide for the Care and Use of Laboratory Animals published by the United State National Institutes of Health (NIH Publication No. 85-23, revised 1996).

\section{Materials}

DIP was provided by Boehringer Ingelheim GmbH (Germany). ASA was obtained from Sigma (St. Louis, MO) and SIM from Merck (Whitehouse Station, NJ). Anti-Akt, antiThr308 P-Akt, and anti-Ser-473 P-Akt antibodies were obtained from R\&D Systems (Minneapolis, MN). AntieNOS, anti-Ser-1177 P-eNOS, anti-ERK 1/2, anti-Thr-202/ Tyr-204 P-ERK 1/2, anti-CREB, and anti-Ser-133 P-CREB antibodies were purchased from Cell Signaling Technology, Inc. (Beverly, MA). Monoclonal anti- $\beta$-actin antibodies were obtained from Sigma.

\section{Treatment}

Rats received either simvastatin $(10 \mathrm{mg} / \mathrm{kg} / \mathrm{d})$ or vehicle (water) by means of oral gavage once daily for 3 days. On the fourth day, the rats were anesthetized with an intraperitoneal injection of ketamine $(60 \mathrm{mg} / \mathrm{kg})$ and xylazine $(6 \mathrm{mg} / \mathrm{kg})$ and were intubated and ventilated $\left(\mathrm{FIO}_{2}=30 \%\right)$. The rectal temperature of the rats was monitored, and their body temperature was maintained between $36.7^{\circ}$ and $37.3^{\circ} \mathrm{C}$ throughout the experiment. After the left carotid artery was cannulated, the chest was opened through the fourth intercostal space. The left coronary artery was encircled with a suture and ligated for $30 \mathrm{~min}$. Five minutes after the start of ischemia, 1 of the following agents was infused intravenously for $120 \mathrm{~min}$ : vehicle (control); high-dose ASA (20 mg/kg, ASA20); low-dose ASA $(2 \mathrm{mg} / \mathrm{kg}$, ASA2); DIP alone $(5 \mathrm{mg} / \mathrm{kg})$; or a 
combination of ASA2 and DIP. Isofluorane (1\%-2.5\%, titrated to effect) was given to the rats after the start of ischemia to maintain anesthesia. After $30 \mathrm{~min}$ of ischemia, the snare was released and myocardial reperfusion was verified by a change in the color of the myocardium. Subcutaneous buprenorphine $(0.1 \mathrm{mg} / \mathrm{kg})$ was administered, the chest was closed. At the end of the infusion (25 min during myocardial ischemia and the first 95 min of reperfusion), the rats were allowed to recover from anesthesia at the end of the infusion. Four hours after reperfusion (IS protocol) and $95 \mathrm{~min}$ after reperfusion (immunobloting), the rats were re-anesthetized, and the coronary artery was reoccluded; $1.5 \mathrm{ml}$ of Evans blue dye $(3 \%)$ was injected into the right ventricle, and the rats were euthanized while under deep anesthesia [13, 16, 17]. The heart rate (HR) and mean blood pressure (MBP) were recorded immediately before coronary artery occlusion, after $20 \mathrm{~min}$ of ischemia, and after $20 \mathrm{~min}$ of reperfusion.

The prespecified exclusion criteria included a lack of signs of ischemia during coronary artery ligation, lack of signs of reperfusion after release of the snare, prolonged ventricular arrhythmia with hypotension, and an area at risk measuring $\leq 10 \%$ of the left ventricular (LV) weight.

\section{Determination of area at risk and infarct size}

The rat hearts were excised, and the left ventricle was sliced transversely into 6 sections. The slices were incubated for $10 \mathrm{~min}$ at $37^{\circ} \mathrm{C}$ in $1 \%$ buffered $(\mathrm{pH}=7.4) 2,3,5$-triphenyltetrazolium-chloride (TTC), and were fixed in a $10 \%$ formaldehyde solution. The sections were photographed to identify the ischemic area at risk (AR)(not colored by the blue dye), the infarct size (IS)(unstained by TTC), and the nonischemic zones (colored by blue dye). In each slice, the AR and IS were determined by means of planimetry, converted into percentages of the whole for each slice, and multiplied by the weight of the slice. The results were summed to obtain the weight of the myocardial AR and IS $[13,16,17]$.

\section{Immunoblotting}

Rats in the control group were treated with water, by means of oral gavage for 3 days, and were not subjected to the ischemia-reperfusion protocol. The other groups were treated as above and exposed to $30 \mathrm{~min}$ of ischemia and $95 \mathrm{~min}$ of reperfusion. There were 4 animals in each group. Myocardial samples from the border of the previously identified ischemic AR zone of the LV wall of treated rats and myocardial samples of control rats were homogenized in lysis buffer $(25 \mathrm{mmol}$ Tris- $\mathrm{HCl}[\mathrm{pH}=7.4], 0.5 \mathrm{mmol}$ EDTA, $0.5 \mathrm{mmol}$ EGTA, $1 \mathrm{mmol}$ phenylmethylsulfonyl fluoride, $1 \mathrm{mmol}$ dithiothreitol, $25 \mathrm{mmol} \mathrm{NaF}, 1 \mathrm{mmol}$
$\mathrm{Na}_{3} \mathrm{VO}_{4}, 1 \%$ Triton $\mathrm{X}-100,2 \%$ sodium dodecyl sulfate [SDS], and $1 \%$ protease inhibitor cocktail). The lysate was centrifuged at $10,000 \times \mathrm{g}$ for $15 \mathrm{~min}$ at $4^{\circ} \mathrm{C}$, and the supernatants were collected. Protein $(50 \mu \mathrm{g})$ was fractionated by SDS polyacrylamide gel electrophoresis (PAGE; $4 \%-20 \%$ ) and transferred to polyvinylidene fluoride membranes (Millipore, Bedford, MA), which were incubated overnight at $4{ }^{\circ} \mathrm{C}$ with primary antibodies. Bound antibodies were detected by using a chemiluminescent substrate (NEN Life Science Products, Boston, MA). The protein signals were quantified with an image-scanning densitometer, and the strength of each protein signal was normalized to the corresponding $\beta$-actin signal. The data are expressed as a percentage of the expression in the control group.

\section{Statistical analysis}

Unless otherwise noted, the data are presented as the mean \pm standard error of the mean. Body weight, left ventricular weight, the size of the area at risk and infarct size, and protein expression were compared by using analysis of variance (ANOVA) with Sidak corrections for multiple comparisons. The differences in HR and MBP were compared by using two-way repeated-measures (treatment $\times$ time) ANOVA with Holm-Sidak multiple comparison procedures. $P<0.05$ was considered statistically significant.

\section{Results}

IS protocol

A hundred rats began the protocol, 4 rats died during the induction of anesthesia ( 1 in the SIM group, 1 in the ASA20 group, 1 in the SIM+ASA20, and 1 in the ASA2+DIP group) and 2 during surgery ( 1 in the ASA20 and 1 in the SIM+ASA20 group). A total of 94 rats were included.

Body weight, left ventricular weight, and area at risk sizes were comparable among groups (Table 1). The IS, expressed as a percentage of the left ventricular weight (Table 1) or as a percentage of the AR (Table 1; Fig. 1), was significantly smaller in the SIM, ASA2+DIP, DIP, SIM+ ASA2, and SIM+ASA2+DIP groups than in the control group. The IS in the ASA2, ASA20, and SIM+ASA20 groups was not significantly different from that in the control group (Table 1; Fig. 1). Both the 3-day pretreatment with SIM alone and the intravenous administration of DIP during occlusion reduced the IS. However, low- or highdose ASA alone $(2 \mathrm{mg} / \mathrm{kg}$ or $20 \mathrm{mg} / \mathrm{kg}$, respectively) administered during occlusion had no effect on IS. In rats pretreated with SIM, however, high-dose ASA blocked the protective IS-limiting effect of SIM. Low-dose ASA did not attenuate the effects of SIM or DIP. The SIM+ASA2+DIP 
Table 1 Body weight, left ventricular weight, area at risk, and infarct size of control and treated rats

\begin{tabular}{llllll}
\hline Treatment group & BW $(\mathrm{g})$ & LV weight $(\mathrm{mg})$ & $\begin{array}{l}\text { Area at risk } \\
(\% \text { of LV weight })\end{array}$ & $\begin{array}{l}\text { Infarct size } \\
(\% \text { of LV weight })\end{array}$ & $\begin{array}{l}\text { Infarct size } \\
(\% \text { of area at risk) }\end{array}$ \\
\hline Control $(n=10)$ & $259 \pm 5$ & $1105 \pm 7$ & $29.3 \pm 0.8$ & $13.5 \pm 1.1$ & $45.7 \pm 2.9$ \\
SIM $(n=11)$ & $259 \pm 2$ & $1110 \pm 2$ & $30.9 \pm 1.1$ & $6.4 \pm 0.3$ & $21.0 \pm 1.5$ \\
ASA2 $(n=10)$ & $257 \pm 3$ & $1110 \pm 4$ & $28.4 \pm 0.7$ & $10.9 \pm 1.1$ & $38.4 \pm 3.5$ \\
ASA20 $(n=10)$ & $258 \pm 3$ & $1112 \pm 4$ & $28.5 \pm 0.8$ & $11.6 \pm 0.9$ & $40.3 \pm 2.7$ \\
ASA2+DIP $(n=10)$ & $259 \pm 3$ & $1115 \pm 4$ & $27.4 \pm 0.8$ & $6.5 \pm 0.5$ & $23.6 \pm 1.7$ \\
DIP $(n=10)$ & $258 \pm 2$ & $1116 \pm 3$ & $29.0 \pm 0.9$ & $7.1 \pm 0.4$ & $24.6 \pm 0.9$ \\
SIM+ASA2 $(n=13)$ & $259 \pm 2$ & $1114 \pm 4$ & $27.2 \pm 0.9$ & $5.4 \pm 0.3$ & $20.0 \pm 1.2$ \\
SIM+ASA20 $(n=10)$ & $259 \pm 1$ & $1115 \pm 3$ & $28.2 \pm 0.7$ & $12.4 \pm 0.5$ & $44.2 \pm 2.1$ \\
SIM+ASA2+DIP $(n=10)$ & $259 \pm 1$ & $1115 \pm 4$ & $28.1 \pm 0.8$ & $3.8 \pm 0.3$ & $13.8 \pm 1.5$ \\
$P$ value & 0.999 & 0.570 & 0.138 & $<0.001$ & $<0.001$ \\
\hline
\end{tabular}

$B W$ body weight; $L V$ left ventricular; SIM simvastatin; DIP dipyridamole; $A S A$ aspirin

group showed the smallest IS (Fig. 1), although the differences between the IS of this group and the IS of the SIM+ASA2 or the SIM-alone groups did not reach statistical significance. The difference between the IS of the SIM+ASA2+DIP and ASA2+DIP groups was of borderline significance $(P=0.061$; Fig. 1$)$.

The HR was unaffected by the different treatments $(P=$ 0.062 ). Although significant changes in HR were observed in all rats from the time of preocclusion to $20 \mathrm{~min}$ after reperfusion $(P<0.001)$, the interaction between treatment and time was not significant $(P=0.166$; Fig. $2 \mathrm{a})$. The MBP significantly decreased from the time of preocclusion to 20 min after reperfusion $(P<0.001$; Fig. $2 b)$, but the difference among the control and treatment groups was

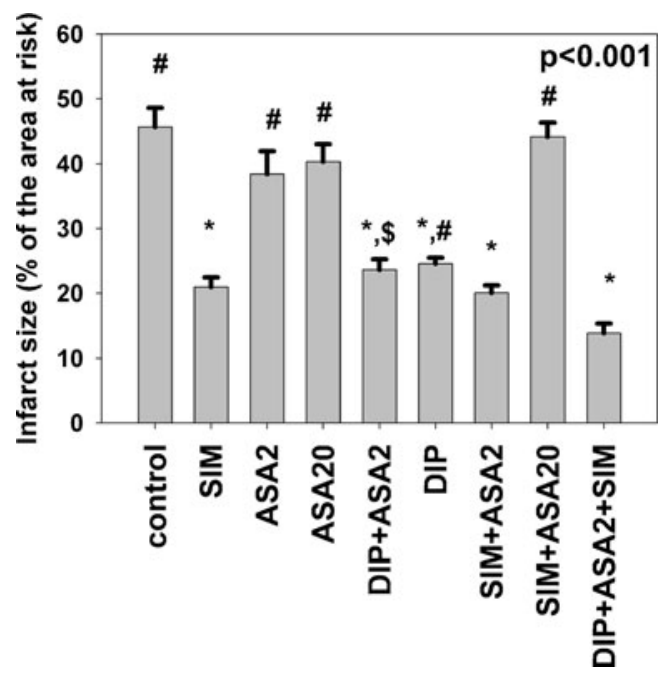

Fig. 1 Myocardial infarct size $(I S)$ shown as a percentage of the area at risk $(A R)$ in control and treatment groups. Data are presented as the mean \pm standard error of the mean. Overall, a significant difference was observed in infarct size among different treatment groups $(P<$ $0.001)$. * $P<0.001$ versus control; \# $P<0.001$ versus DIP+ASA2 +SIM; $\$ P=0.061$ versus DIP+ASA2+SIM not significant $(P=0.062)$. However, with respect to MBP, the interaction between treatment and time was significant $(P=0.001)$. During coronary occlusion, the MBP was significantly lower in the SIM+ASA2+DIP group $(98.6 \pm$ $9.4 \mathrm{mmHg})$ than in the control group $(112.0 \pm 0.3 \mathrm{mmHg})$, the DIP-alone group $(111.7 \pm 2.4 \mathrm{mmHg})$, and the SIM +ASA2 group $(115.5 \pm 2.2 \mathrm{mmHg})$ but not in the ASA2 + DIP group $(106.4 \pm 2.3 \mathrm{mmHg})$. In addition, during coronary occlusion, the MBP was significantly higher in the SIM+ASA2 group $(115.5 \pm 2.2 \mathrm{mmHg})$ than in the SIM +ASA20 group $(104.4 \pm 0.9 \mathrm{mmHg})$ but not in the ASA20only group $(108.0 \pm 2.3 \mathrm{mmHg})$. These differences are not consistent with any of the drugs' known effects and were most likely random. No other significant changes were detected from baseline (preocclusion) to the time of reperfusion.

Immunoblotting

There were 4 animals in each group. The total Akt and total eNOS protein levels were comparable among the treatment and control groups (Fig. 3). Ischemia-reperfusion alone increased myocardial levels of Ser-473 P-Akt and Thr-308 P-Akt compared to controls not subjected to ischemiareperfusion (Fig. 3). SIM and ASA2+DIP increased Ser473 P-Akt and Thr-308 P-Akt levels, whereas ASA20 had no significant effect. For the SIM+ASA20 group, ASA20 did not block the SIM-induced increase in P-Akt levels (Fig. 3), despite blocking the IS-limiting effects of SIM (Fig. 1). The highest levels of Ser-473 P-Akt and Thr-308 P-Akt were seen in the SIM+ASA2+DIP group (Fig. 3).

Ischemia-reperfusion alone caused a mild increase in Ser-1177 P-eNOS levels (Fig. 3). SIM and ASA2+DIP increased P-eNOS levels. ASA20 had no significant effect on P-eNOS levels, and in the SIM+ASA20 group, ASA20 did not block the effect of SIM. No significant differences 

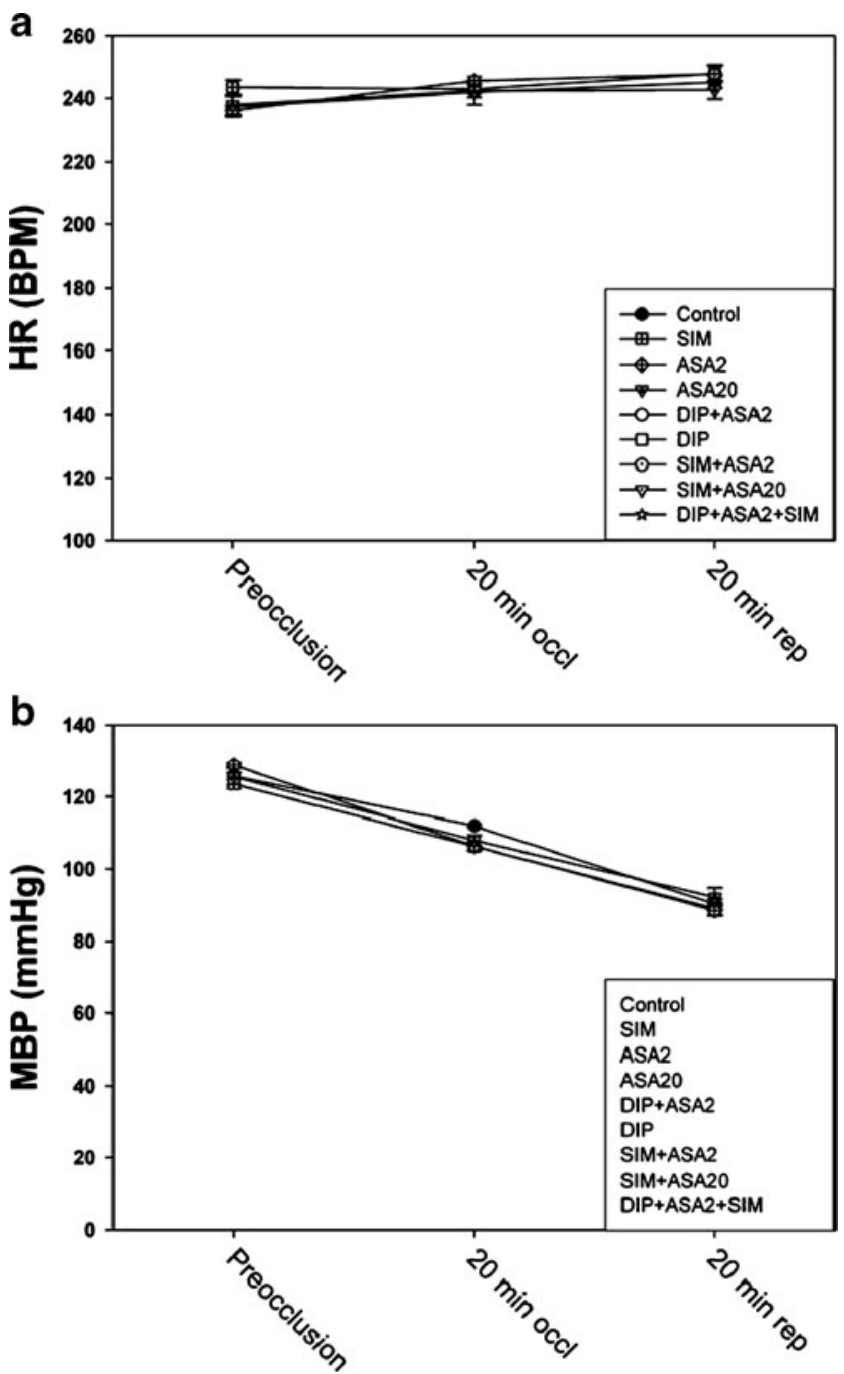

Fig. 2 Heart rate (HR, shown in beats per minute) and mean blood pressure ( $M B P$, shown in $\mathrm{mmHg}$ ) from pre-occlusion to $20 \mathrm{~min}$ after the start of reperfusion. a The different treatments did not significantly affect HR $(P=0.062)$. HR changed significantly over time $(P<0.001)$, but the interaction between treatment and time was not statistically significant $(P=0.166)$. b MBP significantly decreased over time $(P<$ 0.001). Overall, no significant differences were observed in MBP among the treatment groups $(P=0.062)$, although there was a significant interaction between treatment and time $(P=0.001)$

were observed in Ser-1177 P-eNOS levels among the SIM, SIM+ASA20, ASA2+DIP, and SIM+ASA2+DIP groups (Fig. 3).

As shown in Fig. 4, the protein levels of total ERK 1/2 or cyclic AMP response element binding protein (CREB) were comparable among the treatment and control groups. Ischemia-reperfusion alone increased myocardial levels of P-ERK 1/2. ASA20 had no significant effect, whereas SIM alone or with ASA20 augmented myocardial levels of PERK 1/2. DIP+ASA2 increased P-ERK $1 / 2$ levels more than did SIM $(P=0.006)$ or SIM+ASA20 $(P=0.024)$. P-ERK $1 / 2$ levels were significantly higher in the DIP+ASA2+SIM group than those in all other groups, except the DIP+ASA2 group $(P=0.916)$.

Ischemia-reperfusion alone increased P-CREB levels (Fig. 4). ASA20 did not alter the effect of ischemiareperfusion on P-CREB. However, SIM, SIM+ASA20, $\mathrm{DIP}+\mathrm{ASA} 2$, and $\mathrm{DIP}+\mathrm{ASA} 2+\mathrm{SIM}$ increased myocardial levels of P-CREB equally (Fig. 4).

\section{Discussion}

In our study, we showed that the intravenous infusion of DIP ( $5 \mathrm{mg} / \mathrm{kg}$ over $2 \mathrm{~h}$ ), started during myocardial ischemia and continued during the first $95 \mathrm{~min}$ of reperfusion, significantly reduced IS to an extent comparable with 3-day SIM pretreatment, without causing significant hemodynamic changes. Furthermore, when the intravenous infusion of DIP and low-dose ASA was combined with SIM pretreatment, the IS was reduced to an even greater extent than with SIM or DIP alone. Low-dose ASA did not affect the IS-limiting effects of SIM, but high-dose ASA completely blocked the IS-limiting effects of SIM.

Previously, we have shown that pretreating rats with orally administered DIP $(6 \mathrm{mg} / \mathrm{kg} / \mathrm{d})$ and low-dose atorvastatin $(2 \mathrm{mg} / \mathrm{kg} / \mathrm{d})$ limited IS in a synergistic manner [13]. When administered alone, however, neither low-dose atorvastatin nor DIP affected the infarct size. Low-dose atorvastatin and DIP each caused a small increase in myocardial adenosine levels, although when these agents were combined, adenosine levels were significantly increased. Furthermore, only the combination of low-dose atorvastatin and DIP increased myocardial Ser-473 P-Akt and Ser-1177 P-eNOS levels [13]. Aminophylline, a nonselective adenosine receptor blocker, abrogated the ISlimiting effect of DIP and atorvastatin, suggesting that the protective effects of both drugs are mediated by the activation of adenosine receptors.

In our experiments, we used a rate of infusion of DIP $(0.042 \mathrm{mg} / \mathrm{kg} / \mathrm{min})$ significantly lower than the rate used to induce ischemia during pharmacologic stress tests $(0.14 \mathrm{mg} / \mathrm{kg} / \mathrm{min})$; however, we used an absolute dose that is much higher $(5 \mathrm{mg} / \mathrm{kg}$ versus $0.56 \mathrm{mg} / \mathrm{kg}$ ) [3]. DIP blocks the cellular reuptake of adenosine, thus increasing interstitial adenosine levels [1, 2]. DIP causes vasodilation of blood vessels and has antiplatelet effects [1, 2]. In addition, Harker and Kadatz have suggested that DIP is a cAMP phosphodiesterase inhibitor and that it increases the biosynthesis of prostacyclin $\left(\mathrm{PGI}_{2}\right)$ [1].

The IS-limiting effects of statins are dependent on the activation of ecto-5-nucleotidase, which generates adenosine and phosphatidylinositol-3-kinase that promotes the phosphorylation of the pro-survival kinase Akt [14]. The inhibition of adenosine receptors abrogates the IS-limiting 

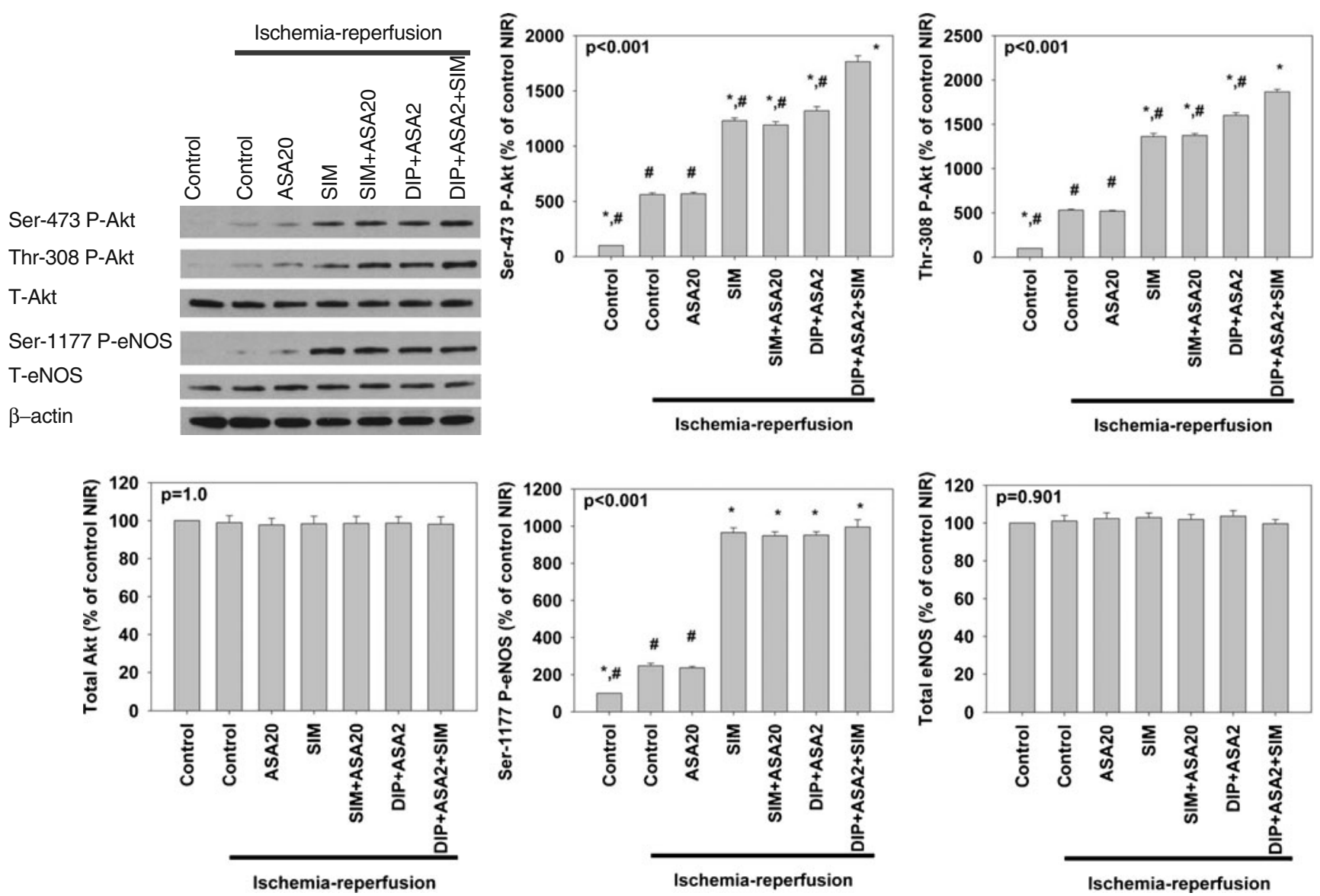

Fig. 3 Representative immunoblots and densitometric analyses of Ser473 P-Akt, Thr-308 P-Akt, total Akt, Ser-1177 P-eNOS, and total eNOS in the border zone of hearts exposed to the ischemia-reprefusion protocol. The myocardium of rats that were not exposed to ischemia- reperfusion and received vehicle served as the control. $\beta$-actin was used as a loading control. ${ }^{*} P<0.001$ versus ischemia-reperfusion control; \# $P<0.001$ versus $\mathrm{DIP}+\mathrm{ASA} 2+\mathrm{SIM}$

phosphorylation induces the translocation of CREB from the cytoplasm to the nucleus where it regulates the transcription of target genes [24]. CREB also binds a cAMP-response element site in the promoter region of genes such as cytochrome $\mathrm{C}$ and $\mathrm{Bcl}-\mathrm{xl}$, which CREB has been shown to positively regulate [30]. CREB is involved in ischemic preconditioning $[22,23]$.

Interestingly, despite the fact that ASA20 blocked the IS-limiting effect of SIM, it did not attenuate the phosphorylation of CREB, suggesting that COX2 functions downstream of CREB activation. Moreover, despite a smaller IS in the DIP+ASA2+SIM group, comparable myocardial levels of P-CREB were observed in the SIM, SIM+ASA20, and DIP+ASA2 groups, suggesting that other signaling pathways are involved in limiting IS.

In addition to activating the cAMP, PKA, and CREB pathways, SIM and DIP+ASA2 activated 2 prosurvival kinases-Akt and ERK 1/2 - that are known to mediate protection against ischemia-reperfusion and reperfusion injury [31, 32]. Although high-dose ASA attenuated the IS-limiting effect of SIM, it did not block the effect of SIM 
on Akt and ERK 1/2 phosphorylation (Figs. 3 and 4), because Akt and ERK 1/2 activation are upstream of COX2 activation [15]. The effects of DIP+ASA2 and SIM on the phosphorylation of Akt were additive when all 3 treatments were combined; this finding paralleled the effect of these agents on myocardial IS. However, it is interesting that DIP+ASA2 increased P-ERK $1 / 2$ levels more than did SIM or SIM+ASA20 (Fig. 4) and that the effect of DIP+ASA2 on ERK 1/2 phosphorylation was comparable to that of $\mathrm{SIM}+\mathrm{DIP}+\mathrm{ASA} 2$, suggesting that there was no additive effect.

As previously described, pretreatment with statins augmented eNOS phosphorylation [13, 14, 17]. eNOS activation is essential for mediating the protective effects of statins, and it is upstream of COX2 activation [33]. In the present study we are showing that DIP+low-dose ASA infusion during ischemia and early reperfusion had equal effect on eNOS phosphorylation as 3-day pretreatment with SIM. However, the combination of SIM with DIP+ASA2 did not result in additive effect on eNOS phosphorylation in myocardium subjected to ischemia-reperfusion. As expected, high-dose ASA did not block the effect of pretreatment with SIM, as COX2 is downstream of eNOS activation [33].

COX2 activation is essential for the IS-limiting effects of statins $[17,18]$. We have previously shown that ASA dose dependently $(5,10$ and $20 \mathrm{mg} / \mathrm{kg})$ attenuated COX2 activity and that COX2 activity inversely correlated with IS [18]. We have also shown that COX2 inhibition abrogates the IS limiting effects of atorvastatin without affecting the upregulation of eNOS phosphorylation and iNOS expression by atorvastatin [17].

We found that ASA20, but not ASA2 attenuated the IS limiting effects of SIM. In the clinical setting, it is recommended that patients with acute ST elevation myocardial infarction will receive chewed aspirin at $160-325 \mathrm{mg} / \mathrm{kg}$ [18]. In Europe an intravenous dose of $250-500 \mathrm{mg}$ is often used. For a $70 \mathrm{~kg}$ patient this represents up to $7.1 \mathrm{mg} / \mathrm{kg}$. Doses of medications given to rats and mice are usually much higher than those used in the clinical setting. We have previously shown that intravenous aspirin (10 and $20 \mathrm{mg} /$

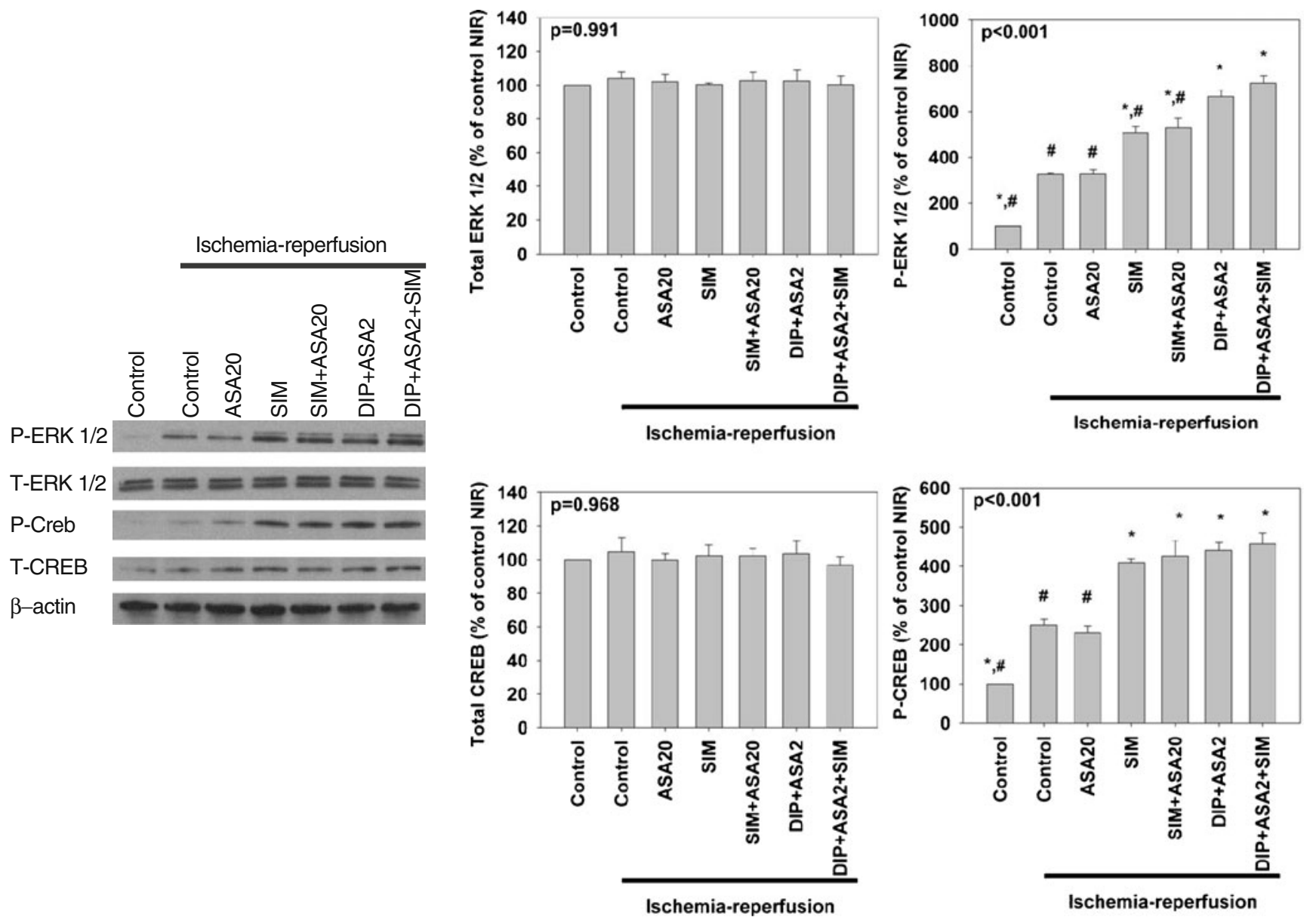

Fig. 4 Representative immunoblots and densitometric analyses of total ERK 1/2, Thr 202/ Tyr-204 P-ERK 1/2, total CREB, and Ser-133 $\mathrm{P}-\mathrm{CREB}$ in the border zone of hearts exposed to ischemia-reperfusion. The myocardium of rats that were not exposed to ischemia-reperfusion and received vehicle served as the control. $\beta$-actin was used as a loading control. $* P<0.001$ versus ischemia-reperfusion control; \# $P<$ 0.001 versus $\mathrm{DIP}+\mathrm{ASA} 2+\mathrm{SIM}$ 
$\mathrm{kg}$ ), administered before reperfusion, attenuates the infarct size limiting effects of atorvastatin [18]. At $5 \mathrm{mg} / \mathrm{kg}$ there is attenuation, but it does not reach statistical significance [18]. Further studies are needed to assess whether such adverse interaction occurs in the clinical setting.

Limitations: in the present study we did not assess the effect of DIP alone without low-dose ASA on the expression of the prosurvival kinases; however, ASA2 did not attenuate the IS-limiting effects of DIP (Fig. 1). Furthermore, we have previously shown that the inhibitory effect of ASA on the IS-limiting effects of atorvastatin is dose dependent and is only minimal at $5 \mathrm{mg} / \mathrm{kg}$ [18]. ASA alone, even at the higher dose, does not affect myocardial IS [18]. The results of our two studies are comparable, showing that at $2 \mathrm{mg} / \mathrm{kg}$, ASA does not attenuate the protective effect of SIM (Fig. 1).

In our model, myocardial infarction is induced in rats by mechanically compressing the artery, rather than by causing the spontaneous formation of a blood clot on a ruptured coronary plaque. In the clinical setting, the inhibition of platelet activity has a significant role in the treatment of acute myocardial infarction [10, 11]. Although DIP+ASA2 have antiplatelet properties, their effects should be compared to those of ASA combined with thienopyridines, which are currently the first-choice agents for inhibiting platelet aggregation per ACC/AHA guidelines. Therefore, studies are warranted that would compare the effects of high-dose ASA with thienopyridine versus low-dose ASA+DIP+thienopyridine; or alternatively, low-dose ASA+DIP versus thienopyridine with ASA in patients receiving statin agents.

In conclusion, when started after coronary artery occlusion and continued during early reperfusion, intravenous infusion of DIP+ASA2 appeared to be safe and was not associated with significant hemodynamic changes. Furthermore, DIP+ASA2 was associated with a significant reduction in the myocardial IS and with activation of the prosurvival kinases Akt and ERK $1 / 2$, CREB, and eNOS. Thus, the combination of DIP and low-dose ASA should be considered as an alternative to the higher dose ASA currently used, especially in patients receiving statins. Further studies are needed to verify if such interactions occur in the clinical setting.

Open Access This article is distributed under the terms of the Creative Commons Attribution Noncommercial License which permits any noncommercial use, distribution, and reproduction in any medium, provided the original author(s) and source are credited.

\section{References}

1. Harker LA, Kadatz RA. Mechanism of action of dipyridamole. Thromb Res Suppl. 1983;4:39-46.
2. Schaper W. Dipyridamole, an underestimated vascular protective drug. Cardiovasc Drugs Ther. 2005;19:357-63.

3. Ali Raza J, Reeves WC, Movahed A. Pharmacological stress agents for evaluation of ischemic heart disease. Int $\mathrm{J}$ Cardiol. 2001;81:157-67.

4. Sacco RL, Diener HC, Yusuf S, et al. Aspirin and extendedrelease dipyridamole versus clopidogrel for recurrent stroke. $\mathrm{N}$ Engl J Med. 2008;359:1238-51.

5. Heidland UE, Heintzen MP, Michel CJ, Strauer BE. Intracoronary administration of dipyridamole prior to percutaneous transluminal coronary angioplasty provides a protective effect exceeding that of ischemic preconditioning. Coron Artery Dis. 2000;11:607-13.

6. Heintzen MP, Heidland UE, Klimek WJ, et al. Intracoronary dipyridamole reduces the incidence of abrupt vessel closure following PTCA: a prospective randomised trial. Heart 2000;83:551-6.

7. Heidland UE, Heintzen MP, Michel CJ, Strauer BE. Adjunctive intracoronary dipyridamole in the interventional treatment of small coronary arteries: a prospectively randomized trial. Am Heart J. 2000;139:1039-45.

8. Yoshida Y, Hirai M, Yamada T, et al. Antiarrhythmic efficacy of dipyridamole in treatment of reperfusion arrhythmias: evidence for cAMP-mediated triggered activity as a mechanism responsible for reperfusion arrhythmias. Circulation 2000;101:624-30.

9. Thompson PL, Aylward PE, Federman J, et al. A randomized comparison of intravenous heparin with oral aspirin and dipyridamole 24 hours after recombinant tissue-type plasminogen activator for acute myocardial infarction. National Heart Foundation of Australia Coronary Thrombolysis Group. Circulation 1991;83:1534-42.

10. Antman EM, Anbe DT, Armstrong PW, et al. ACC/AHA guidelines for the management of patients with ST-elevation myocardial infarction; A report of the American College of Cardiology/American Heart Association Task Force on Practice Guidelines (Committee to Revise the 1999 Guidelines for the Management of patients with acute myocardial infarction). J Am Coll Cardiol. 2004;44:E1-211.

11. Antman EM, Hand M, Armstrong PW, et al. 2007 focused update of the ACC/AHA 2004 guidelines for the management of patients with ST-elevation myocardial infarction: a report of the American College of Cardiology/American Heart Association Task Force on Practice Guidelines. J Am Coll Cardiol. 2008;51:210-47.

12. Kushner FG, Hand M, Smith Jr SC, et al. 2009 focused updates: ACC/AHA guidelines for the management of patients with ST-elevation myocardial infarction (updating the 2004 guideline and 2007 focused update) and ACC/AHA/SCAI guidelines on percutaneous coronary intervention (updating the 2005 guideline and 2007 focused update) a report of the American College of Cardiology Foundation/American Heart Association Task Force on Practice Guidelines. J Am Coll Cardiol. 2009;54:2205-41.

13. Ye Y, Lin Y, Perez-Polo R, et al. Enhanced cardioprotection against ischemia-reperfusion injury with a dipyridamole and lowdose atorvastatin combination. Am J Physiol Heart Circ Physiol. 2007;293:H813-8.

14. Sanada S, Asanuma H, Minamino T, et al. Optimal windows of statin use for immediate infarct limitation: $5^{\prime}$-nucleotidase as another downstream molecule of phosphatidylinositol 3-kinase. Circulation 2004;110:2143-9.

15. Merla R, Ye Y, Lin Y, et al. The central role of adenosine in statininduced ERK1/2, Akt, and eNOS phosphorylation. Am J Physiol Heart Circ Physiol. 2007;293:H1918-28.

16. Atar S, Ye Y, Lin Y, et al. Atorvastatin-induced cardioprotection is mediated by increasing inducible nitric oxide synthase and consequent S-nitrosylation of cyclooxygenase-2. Am J Physiol Heart Circ Physiol. 2006;290:H1960-8. 
17. Birnbaum Y, Ye Y, Rosanio S, et al. Prostaglandins mediate the cardioprotective effects of atorvastatin against ischemiareperfusion injury. Cardiovasc Res. 2005;65:345-55.

18. Birnbaum Y, Lin Y, Ye Y, et al. Aspirin before reperfusion blunts the infarct size limiting effect of atorvastatin. Am J Physiol Heart Circ Physiol. 2007;292:H2891-7.

19. Schulte G, Fredholm BB. Signalling from adenosine receptors to mitogen-activated protein kinases. Cell Signal. 2003;15:813-27.

20. Inserte J, Garcia-Dorado D, Ruiz-Meana $M$, et al. Ischemic preconditioning attenuates calpain-mediated degradation of structural proteins through a protein kinase A-dependent mechanism. Cardiovasc Res. 2004;64:105-14.

21. Sanada S, Asanuma H, Tsukamoto O, et al. Protein kinase A as another mediator of ischemic preconditioning independent of protein kinase C. Circulation 2004;110:51-7.

22. Marais E, Genade S, Lochner A. CREB activation and ischaemic preconditioning. Cardiovasc Drugs Ther. 2008;22:3-17.

23. Nagy N, Shiroto K, Malik G, et al. Ischemic preconditioning involves dual cardio-protective axes with p38MAPK as upstream target. J Mol Cell Cardiol. 2007;42:981-90.

24. Shaywitz AJ, Greenberg ME. CREB: a stimulus-induced transcription factor activated by a diverse array of extracellular signals. Annu Rev Biochem. 1999;68:821-61.

25. Kwak HJ, Park KM, Choi HE, et al. PDE4 inhibitor, roflumilast protects cardiomyocytes against NO-induced apoptosis via activation of PKA and Epac dual pathways. Cell Signal. 2008;20: 803-14.
26. Das S, Tosaki A, Bagchi D, Maulik N, Das DK. Resveratrolmediated activation of cAMP response element-binding protein through adenosine A3 receptor by Akt-dependent and -independent pathways. J Pharmacol Exp Ther. 2005;314:762-9.

27. Frodin M, Gammeltoft S. Role and regulation of $90 \mathrm{kDa}$ ribosomal S6 kinase (RSK) in signal transduction. Mol Cell Endocrinol. 1999;151:65-77.

28. Li B, Kaetzel MA, Dedman JR. Signaling pathways regulating murine cardiac CREB phosphorylation. Biochem Biophys Res Commun. 2006;350:179-84.

29. Ozgen N, Obreztchikova M, Guo J, et al. Protein kinase D links Gq-coupled receptors to cAMP response element-binding protein (CREB)-Ser133 phosphorylation in the heart. J Biol Chem. 2008;283:17009-19.

30. Eliseev RA, Vanwinkle B, Rosier RN, Gunter TE. Diazoxidemediated preconditioning against apoptosis involves activation of cAMP-response element-binding protein (CREB) and NFkappaB. J Biol Chem. 2004;279:46748-54.

31. Hausenloy DJ. Signalling pathways in ischaemic postconditioning. Thromb Haemost. 2009;101:626-34.

32. Hausenloy DJ, Tsang A, Yellon DM. The reperfusion injury salvage kinase pathway: a common target for both ischemic preconditioning and postconditioning. Trends Cardiovasc Med. 2005;15:69-75.

33. Ye Y, Martinez JD, Perez-Polo RJ, et al. The role of eNOS, iNOS, and NF-kappaB in upregulation and activation of cyclooxygenase2 and infarct size reduction by atorvastatin. Am J Physiol Heart Circ Physiol. 2008;295:H343-51. 